\title{
O SIGNIFICADO MODAL E O USO PARENTÉTICO: UMA INVESTIGAÇÃO DOS VERBOS COGNITIVOS NO PORTUGUÊS
}

\author{
MODAL MEANING AND PARENTHETIC USE: \\ AN INVESTIGATION OF COGNITIVE VERBS IN \\ PORTUGUESE
}

Letícia de Almeida Barbosa*

\begin{abstract}
Resumo: Este artigo analisa as nuances de alguns verbos cognitivos do português, com objetivo de identificar quais acepções proporcionam a sua atuação no campo da cognição e no campo da modalidade epistêmica. Com base em Casseb-Galvão (1999), Traugott e Dasher (2001) e Barbosa-Santos (2019), pode-se notar que, de codificadores de processos mentais, os verbos acreditar, pensar, imaginar e calcular passam a ocorrer como modalizadores, com visível saliência de seu sentido epistêmico. Para coleta e análise dos predicados, optou-se por ocorrências entre os séculos XVIII e XX, no Corpus do Português. A escolha do corpus se justifica pelo fato de ele compor um conjunto amplo de construções da língua entre os séculos investigados. Por meio das ocorrências analisadas, pode-se constatar que, embora tais verbos expressem opinião e crença, há um continnum de nunces mais e menos específicas, que permitem os definir como mais ou menos fluidos.
\end{abstract}

Palavras-chave: abstratização; nuances; verbos cognitivos.

Aвstract: This article analyses the nuances of the cognitive verbs from Portuguese, in order to identify which meanings provide their works in the field of cognition and in the field of epistemic modality. Based on Casseb-Galvão (1999), Traugott and Dasher (2001) and Barbosa-Santos (2019), it can be noted that, from being coders of mental processes, the verbs acreditar, pensar, imaginar and calcular start to occur as modalizers, with a visible salience of their epistemic sense. To collect and analyze these verbs, it was chose occurrences between the XVIII to XX centuries, in the Corpus do Português. For the collection and analysis, occurrences between the 18th and 2oth centuries were chosen, in the Corpus do Português. The choice is justified by the fact that it comprises a wide range of language constructions between the centuries investigated. Through the occurrences, it was seen that, although such verbs express

\footnotetext{
" Mestre em Letras/Linguística pela Universidade Federal de Mato Grosso do Sul e, atualmente, cursa Doutorado em Estudos Linguísticos pela Universidade Estadual Paulista - Ibilce. E-mail: leticiaalmeidabarboza@gmail.com.
} 
opinion, there is a continnum of more and less specific nunces, which allow us to define them as more or less fluid.

KEYwoRDs: abstratization; nuances; cognitive verbs.

\section{INTRODUÇÃo}

A relação entre modalidade epistêmica e a parentetização de verbos cognitivos tem sido alvo de investigação em diversos trabalhos de cunho funcionalistas, dentre eles o de CassebGalvão (1999, 2000), Traugott e Dasher (2001), Gonçalves (2003) e Barbosa-Santos (2019). Tais estudos vêm se ocupando da tarefa de analisar e descrever o funcionamento sintático, semântico e pragmático desses usos, considerando, assim, fenômenos que vêm ocorrendo com esses predicados.

Para esses autores, a parentetização configura-se como uma ressalva utilizada pelo locutor a fim de se resguardar de possíveis questionamentos diante de sua afirmação, uma vez que ela pode ou não ser verdadeira. Esse processo está relacionado ao que Castilho e Castilho (1993) define como modalidade epistêmica, visto que, por meio dela, evidenciam-se os graus de incerteza sobre a verdade da proposição.

Considerando que os verbos cognitivos, objeto de análise deste trabalho, são os que, no âmbito do pensamento, dão origem a percepções, conhecimentos, crenças ou julgamentos, observa-se a correlação entre o processo de parentetização e a expressão de nuance modal, o que proporciona a esses predicados a atuação de advérbios modalizadores.

As ocorrências abaixo ilustram o funcionamento prototípico dos verbos que aqui se propõe analisar. Esse uso mais conservador caracteriza-se pelo encaixamento sintático, quando eles se encontram ainda em uma construção matriz, funcionando, portanto, como verbos plenos.

(1) Eu creio que ele $(\mathrm{FHC})$ até poderá se reeleger, mas, claro, tem que se submeter às urnas. (Dom Cláudio Hummes, 06-8-97)

(2) Suponho que Vossas Mercês já estarão satisfeitos de obras boas desses dois compositores que saíram. (Entremezes de Cordel - José Daniel Rodrigues da Costa, 1807)

(3) Tenho muitos amigos na Itália, mas reconheço que certas pessoas têm uma má imagem de mim. (Antonio Negri - 30 junho 1997)

(4) Destas palavras deduzo que Prado está completamente demudado. É claro que para pior. (Cartas a Emília - Ramalho Ortigao, 1888)

Em relação à natureza dos verbos de cognição, prototipicamente, constata-se que tais predicados encaixam orações na condição de argumento interno, expressando um processamento mental relacionado ao conhecimento e avaliação do locutor. De verbos plenos e 
codificadores de processos mentais, os itens têm ocorrido como parentéticos, podendo ser observados nas ocorrências (5) e (6):

(5) Não comporia bolas envenenadas, suponho, mas não as recusaria também. O que faria com certeza era ir atrás dos cães, a pedrada, até onde lhe dessem as pernas. (18:Machado:Casmurro/Machado de Assis)

(6) Por mais difícil que seja para nós entendê-los, é só isso que te peço, que percebas por trás das aparências morais de nossa pequena sociedade e das regras que, eu entendo, precisam ser respeitadas, a impetuosidade desses jovens como um erro inocente. (19:Fic:Br:Carvalho, Bernardo: Bêbados, 1999)

Em configuração parentética, parece haver saliência da nuance epistêmica, que se considera presente nesses verbos. A hipótese elucidada, neste trabalho, é que alguns verbos de cognição se aproximam mais da modalidade epistêmica, pelo fato de possuírem acepções que favorecem o intercâmbio entre o eixo da modalidade e o eixo da cognição, e outros, devido à especificidade do processo que expressam, mostram-se mais distantes da expressão de crença e opinião, mantendo nuances menos abstratas, como ocorre com o verbo calcular que, embora seja recrutado para o uso parentético em contextos modais, ainda apresenta acepções bastante ligadas a um processo computacional. Nesse sentido, analisa-se, aqui, o conjunto de acepções dos predicados acreditar, pensar, imaginar e calcular, que, apesar de parentetizados, evidenciam diferentes comportamentos que serão descritos a seguir.

\section{APORTES TEÓRICO-METODOLÓGICOS}

Na seção a seguir, serão apresentados os pressupostos teóricos e metodológicos utilizados na pesquisa, bem como alguns conceitos que sustentam a relação entre modalidade e parentetização dos verbos cognitivos. Tais análises encontram-se amparadas por estudos como os de Neves (1996), Traugott (1986; 2003), Traugott e Dasher (2001), Jubran (2006) e BarbosaSantos (2019). Assim, por meio das análises do uso parentético e o significado modal expresso pelos predicados acreditar, pensar, imaginar e calcular, será possível notar que, dentro de um mesmo conjunto, há particularidades no que diz respeito às características semânticas de cada predicado. Abaixo, serão tecidas algumas teorizações acerca do processo de parentetização e saliência de modalidade entre os dados analisados.

\section{VeRbos COGNITIVOS, MODALIDADE EPISTÊMICA E PARENTETIZAÇÃo}

Considerando que os verbos cognitivos selecionados para este trabalho possuem acepções que podem aproximá-los ou distanciá-los da expressão de modalidade epistêmica, faz-se necessário retomar algumas considerações acerca da modalização, visto que é por meio desse 
recurso que, linguisticamente, o locutor é capaz de apresentar a sua atitude e crença diante de um conteúdo proposicional.

Com objetivo de revelar a sua avaliação, o locutor faz uso de vários elementos textuais que evidenciam suas percepções, crenças e posicionamentos acerca de um conteúdo. Nesse âmbito, a modalização aqui delineada caracteriza-se como um recurso que permite explicitar o (des)comprometimento do locutor com a verdade do conteúdo, levando-o a afirmar algo e, ao mesmo tempo, não se comprometer totalmente com a verdade do que está sendo dito.

De acordo com Neves (1996, p. 174):

no extremo da certeza, o enunciador avalia como verdadeiro o seu enunciado, apresentando uma asseveração (afirmação ou negação), sem dar espaço para dúvida e sem relativização. Por outro lado, o falante pode utilizar os chamados 'elementos de relativização', por apresentar, ao lado de elementos que expressam certezas (asseveração), elementos que expressam a não-certeza (relativização), fazendo ressalvas e não perdendo, portanto, a credibilidade.

As estratégias de modalização, segundo Neves (1996), além de demonstrarem a relação entre o locutor e o conteúdo proposicional, evidenciam a preocupação em relação à aceitabilidade, por parte do interlocutor, daquilo que está sendo afirmado, uma vez que o interlocutor pode ou não concordar com a afirmação apresentada.

Na esteira dos estudos sobre a modalidade epistêmica, Palmer (1986) tece uma discussão distinguindo três tipos de julgamentos comuns na linguagem: a expressão de incerteza; a indicação de inferência a partir de evidências e a indicação de inferência seguido daquilo que é, de fato, conhecido. Esses três tipos são definidos pelo autor como: i) meio especulativo; ii) meio dedutivo; iii) meio hipotético. Abaixo, seguem alguns exemplos utilizados em Palmer (1986):

(1)

i. John may be in his Office.

(John pode estar em seu escritório)

ii. John must be in his office.

(John deve estar em seu escritório)

iii. John'll be in his Office.

(John estará em seu escritório)

Com base nesses exemplos, o autor explica que a primeira marca de incerteza do locutor pode ser vista em 1.i, pois o verbo may indica que a afirmação está entre o possível e o não possível, uma vez que pode ou não ser confirmada. Com o uso do must, em 1.ii, o julgamento toma por base evidencias disponíveis no contexto, sendo assim, o fato de as luzes do escritório estarem acesas serve de inferência ao locutor de que John está em seu escritório. 
Em 1.iii, o locutor, ao dizer "John estará em casa", tece um julgamento com base no que ele conhece sobre John. Segundo Palmer (1986), a distinção entre may e must deve-se ao fato de o primeiro consistir no que é epistemicamente possível e, o segundo, no que é epistemicamente necessário. Em consonância ao posicionamento do locutor, por meio do uso da linguagem, Traugott (1989, p. 34-35) apresenta três tendências ${ }^{1}$ de aumento de expressividade/subjetividade na língua. A primeira tendência postula que os significados baseados em situações externas passam a descrever significados avaliativos, perceptivos e cognitivos, ou seja, significados baseados no mundo biofísico tendem a expressar significados mentais.

A segunda tendência afirma que significados baseados em situações internas ou externas podem passar a ser baseados na situação textual e metalinguística, e a terceira tendência, também apresentada em Traugott (1989), baseia-se no fato de que os significados tendem a se tornar cada vez mais ligados à crença e à atitude em relação à proposição. Ressalta-se que o processo de subjetivação é caracterizado, em Traugott (2003), como um processo semasiológico por meio do qual os locutores, ao longo do tempo, desenvolvem significados novos para formas já existentes, passando a codificar perspectivas e atitudes baseadas nas características do evento comunicativo e não do evento do mundo real.

O processo de parentetização, que dá ênfase à expressão de modalidade entre os verbos cognitivos, é definido em Jubran (2006) como uma modalidade de inserção, caracterizando-se por uma breve suspensão do tópico discursivo. Esse recurso não constitui uma nova centração tópica, e não afeta, portanto, a coesão do tópico dentro do qual ocorrem (JUBRAN, 2006, p. 303). Tal definição mostra a possibilidade de tratar os verbos de cognição, sobretudo os que são analisados nesse trabalho, como parentéticos, pois suspendem momentaneamente o tópico em que ocorrem.

Conforme Schneider (2007), ao analisar o fenômeno da parentetização de verbos, notam-se algumas características sintáticas, semânticas e pragmáticas importantes, são elas: i. o fato de terem seu próprio contorno entoacional, comportando-se, portanto, como uma pequena sentença; ii. a falta de um vínculo sintático expresso por algum conector; iii. a relação pragmática que mantém com a oração "hospedeira"; iv. a interrupção prosódica que causa na sentença "hospedeira" e v. a função interpessoal fortemente presente. Esses fatores atribuem aos predicados verbais características de advérbio, uma vez que permite uma maior mobilidade sentencial e uma clara independência sintática.

Entre os estudos que relacionam modalização e parentetização, situa-se o trabalho de Traugott e Dasher (2001, p. 107), que, ao analisarem a expressão cristalizada I promise you, elencam um aumento de subjetivação, via parentetização da construção formulaica em que

\footnotetext{
"Tendency I: meanings based in the external described situation > meanings based in the internal (evaluative/perceptual/cognitive) described situation. Tendency II: meanings based in the external or internal described situation > meanings based in the textual and metalinguistic situation. Tendency III: meanings tend to become increasingly based in the speaker's subjective belief state/attitude toward the proposition" (TRAUGOTT, 1989, p. 34-35).
} 
promise aparece. Os autores consideram que, além de ser subjetivamente modalizada, traz em si mesma um alto grau de intersubjetividade, ou seja, de direcionamento dos significados ao ouvinte, devido à preocupação do locutor em relação à interpretação que o outro terá ao receber e interpretar o enunciado. Nesse sentido, há uma afirmação e, em seguida, uma ressalva, por considerar que o seu ouvinte pode apresentar alguma discordância em relação à veracidade do conteúdo. Os autores também rotulam tais expressões como epistêmicas, o que ocorre de forma semelhante em Bybee (2010), que apresenta algumas construções com os verbos can, think e believe, considerando-os, também, cognitivos/epistêmicos.

No âmbito do conhecimento e expressão de avaliação por parte do locutor, os processos de subjetividade e intersubjetividade atuam da seguinte maneira: enquanto o primeiro consiste na exposição do que é próprio do locutor em relação ao conteúdo, o segundo relaciona-se a preocupação do locutor em relação ao modo como o interlocutor receberá a informação, assim, são utilizados recursos para se resguardar de possíveis questionamentos.

Dentro da categoria verbo, há vários predicados que expressam diferentes ações, processos e atividades que permitem ao locutor suavizar o conteúdo veiculado no interior da comunicação. Observando alguns trabalhos acerca da distinção e caracterização de tais elementos, pode-se notar que alguns autores postulam a existência de um continuum, em que itens mais próximos da realidade humana são considerados mais concretos em relação a itens que expressam ações ou atividades mais distantes do mundo material, o que fazem deles mais abstratos. Dentre os verbos codificadores de processos mais abstratos, diferentes subclasses podem ser apontadas, de acordo com suas características semânticas. Com base em Halliday (1985, p. 117), nota-se que os verbos de cognição fazem parte de um dos subtipos de processos mentais composto por verbos como pensar, sentir e ver, que, por desempenharem uma ação na mente, não apresentam evidência no mundo biofísico.

Considerando que, segundo Halliday (1985, p. 115-119), de modo geral, o grupo de verbos cognitivos encontra-se subdividido em: i) verbos que expressam processos mentais de percepção, como ouvir, ver, sentir; ii) verbos que denotam processos mentais de afeição, como amar e gostar; iii) verbos que desenvolvem processos mentais de cognição, que são representados pelos predicados entender, pensar, lembrar, esquecer e planejar. É possível identificar, nesse último conjunto, os verbos acreditar, pensar, imaginar e calcular, que desenvolveram, ao longo do tempo, processos mentais intimamente ligados à expressão de opinião.

Schlesinger (1995, p. 181), ao trazer uma caracterização dos predicados verbais, organiza-os hierarquicamente, considerando as nuances que eles expressam, e delineando, assim, o grau de atividade mental que desempenham. Ao fazer a distinção, o autor apresenta algumas categorias que distinguem alguns predicados, elencando que os verbos de atividades mais palpáveis são os que dão origem a uma imagem relativamente concreta, por estarem mais ligadas ao mundo biofísico. Outra categoria explicitada pelo autor é de cognição e percepção, que 
abarcam os verbos de estímulo mental, cujo sujeito da oração serve de estímulo para outro, e os verbos de experimentação mental, cujo sujeito da oração é o próprio locutor.

Consoante Tavares e Freitag (2010, p. 104), os tipos de verbos podem ser associados às nuanças concreta, abstrata e genérica, o que possibilita uma observação dos diferentes graus de gramaticalização². Ainda segundo as autoras:

Quanto maior o traço de atividade do verbo, mais ele sinalizará nuanças concretas, referindo-se a ações físicas sobre o mundo exterior, isto é, o mundo das experiências básicas e intencionais. À medida que vai descendo os degraus da escala de atividade, mais o verbo expressa nuanças abstratas/genéricas, perdendo pouco a pouco os elos com o mundo concreto e com a ação física intencional sobre esse mundo, chegando à expressão de operações cognitivas que não codificam ação física, mas sim mental. Por sua vez, os verbos que ocupam a ponta final da escala de atividade são bastante generalizados, pouco carregado de significado em si e servindo basicamente como elo de ligação para seus complementos. Relacionam-se, portanto, a nuanças genéricas (TAVARES; FREITAG, 2010, p. 104).

Conforme as autoras, há uma gradualidade que permite a abstratização do predicado verbal, levando-o a descer degraus da escala de atividade e, consequentemente, evidenciando nuances mais fluidas. Ao observar as nuances encontradas em cada tipo de verbo analisado nesse trabalho, contatou-se que, embora façam parte de uma mesma categoria, apresentam acepções semântico-pragmáticas que os diferenciam em diversos aspectos, principalmente, quando os predicados em questão apresentam a tendência de se parentetizarem e perderem flexão de tempo e modo.

Com base nos pressupostos discutidos até aqui e a partir da relação entre a modalidade epistêmica e parentetização, são delineados, nesse trabalho, as características que permitem alguns verbos serem considerados mais abstratos que outros e, devido a isso, estarem mais propensos à expressão modal, já outros, por serem típicos de um processo menos abstrato, estão mais distantes do campo epistêmico, fato que evidencia um continnum dentro de um mesmo conjunto. Portanto, a seguir, serão apresentados os aportes metodológicos utilizados na pesquisa e, em seguida, a análise contendo os resultados encontrados.

\footnotetext{
${ }^{2}$ Por Gramaticalização entende-se, com base em Hopper e Traugott (1993), o processo pelo qual há a busca por maior expressividade, levando itens lexicais a desempenharem funções gramaticais e itens já gramaticais a aumentarem ainda mais a sua gramaticalidade, tornando-se, assim, ainda mais abstratos ao longo do tempo.
} 


\section{Metodologia da PESQUisa}

Quanto à metodologia adotada para este estudo, para a análise dos verbos acreditar, pensar, imaginar e calcular, optou-se pelo levantamento de ocorrências disponíveis no banco de dados do Corpus do Português (DAVIES; FERREIRA, 2006)33 devido ao seu acervo que contém conjuntos significativos de textos de diferentes gêneros, do século XIV até a atualidade. Com relação a sua composição, esse corpus disponibiliza aos usuários ferramentas de busca de construções fornecendo inclusive sua frequência. Foram coletadas ocorrências do século XXI, retiradas do Web/Dialetos, que compõem a nova edição do corpus, fornecendo um acervo com cerca de um bilhão de palavras de textos retirados da web.

Como critério de seleção, abrangeram-se tanto dados do Português Brasileiro quanto dados do Português Europeu, especificamente de Portugal, pois, para o fenômeno aqui analisado, não se observaram distinções relacionadas ao seu funcionamento. A partir das ocorrências, buscou-se investigar, por meio de uma análise qualitativa, se, de fato, há nuances semânticas em cada verbo que o mantém mais arraigado no eixo da cognição e outras que levam o verbo na direção da modalidade epistêmica.

A hipótese que fundamenta esta pesquisa assenta-se no pressuposto de que a especificidade do processo cognitivo expresso por alguns verbos "freie" sua trajetória rumo a uma maior expressividade de postura epistêmica do locutor e à parentetização. Parece plausível que alguns verbos de cognição se aproximam mais do campo epistêmico, enquanto outros permanecem mais "conservadores", mantendo a especificidade de revelar uma ação mental/ cognitiva.

Para análise das acepções de cada verbo, optou-se por Borba (1990), Ferreira (2002), Michaelis (2008) e Cunha (2010). Ressalta-se que, em Borba (1990), são apresentados registros das diferentes acepções, bem como uma classificação sintático-semântica que se caracteriza a partir da estruturação da frase, partindo do núcleo do predicado em torno do qual os demais componentes se arranjam em diferentes graus de coesão e dependência. Nesse sentido, ao analisar os significados dos verbos selecionados, pode-se notar uma trajetória de abstratização, que é permitida por meio da atuação de processos como a subjetivação, que permite a extensão de significados, levando esses verbos a se generalizarem na escala de usos modais.

A seção seguinte apresentará as análises das ocorrências dos predicados aqui selecionados, dando ênfase a aspectos peculiares que permitem uma distinção dentro do grupo analisado. Com o aprofundamento das nuances que integram cada verbo, pode-se evidenciar que o verbo cognitivo nem sempre é epistêmico por origem, mas, por meio de processos sintáticos e semânticos, surge a possibilidade de um recrutamento que permite o seu funcionamento enquanto modalizador.

${ }^{3}$ Disponível em: https://www.corpusdoportugues.org. 


\section{ANÁLISE E INTERPRETAÇÃO DAS OCORRÊNCIAS}

\section{AS NUANCES DOS VERBOS COGNITIVOS ACREDITAR, PENSAR, IMAGINAR E CALCULAR}

Considerando as questões pontuadas até aqui, será possível notar, por meio de algumas análises, que alguns verbos possuem acepções que proporcionam um elo entre o eixo cognitivo e a expressão de modalidade epistêmica, pelo fato de não codificarem uma atividade mental muito concreta. Barbosa-Santos (2019) mostra que, embora exista um consenso de que verbos cognitivos são também epistêmicos, quando se analisa a semântica de cada predicado, evidencia-se que nem todos os verbos de cognição expressam, inicialmente, modalidade epistêmica, ou seja, nem todos os verbos de processo mental carregam expressão modal desde sua origem.

Em relação à sintaxe desses predicados, de acordo com Hengeveld e Mackenzie (2008), os verbos cognitivos selecionam, como segundo argumento, conteúdos proposicionais, isto é, conteúdos que expressam as suposições do locutor em relação ao conteúdo, o que se relaciona à modalidade epistêmica, no que diz respeito à crença e ao posicionamento. Consonante a esse pressuposto, Neves (2011, p. 32) considera que, semanticamente, os verbos cognitivos podem ser alocados entre os factivos, pois se configuram como predicados que têm a possibilidade de implicar a factualidade ou não factualidade de determinado estado de coisas.

Considerando as caracterizações a respeito dos predicados aqui analisados e retomando a hipótese elucidada anteriormente, alguns verbos, como achar e acreditar mostram-se mais suscetíveis à mudança, pelo fato de apresentarem processos cognitivos mais fluidos, não sendo tão representativos de uma atividade mental. Ao analisar a semântica do verbo acreditar, percebe-se que o seu significado faz referência ao ato de aceitar como verdadeiro ou estar convencido da verdade, o que mostra uma aproximação maior ao eixo da modalidade epistêmica, uma vez que, para convencer-se de algo, é necessário posicionar-se subjetivamente.

Um exemplo contrário ao verbo citado acima, o acreditar, pode ser dado por meio do verbo calcular, que está bastante ligado a uma atividade mental específica de concluir algo por raciocínio e inferência do locutor, mostrando-se bastante ligado ao eixo da cognição, fato que dificulta o seu desvio para o campo epistêmico, pela não perda das nuances do processo de origem.

Observando a semântica do verbo acreditar, é possível perceber um alto grau de subjetividade, uma vez que o seu próprio processamento mental está relacionado ao ato de crer, dar crédito, ter como verdadeiro. Esse verbo é fortemente subjetivo, e se encontra muito próximo da modalidade epistêmica e que permite expressão de posicionamento em relação ao conteúdo proposicional. Assim, pelo fato de ele processar uma atividade mental mais ampla, que não especifica um processo cognitivo mais concreto, ele liga-se à modalidade epistêmica 
mais facilmente. As ocorrências abaixo ilustram tal processamento, ao longo dos diferentes contextos em que o predicado acreditar pode ocorrer:

(7) Eu estou lapidando, deixando o mais perfeito possível, mas acredito no potencial dela. (19Or:Br:Intrv:Cid - Simone Magalhaes, 1800)

(8) Achamos que o Governo é isto que está aí. E até o final, vai ser isso. O que se conseguiu fazer até aqui, conseguiu. Mas daqui pra frente, não acredito em alterações significativas. (19Or:Br:Intrv:Com-Manoel dos Santos, 1997)

(9) Eu acredito que o ex-secretário Geraldo Eugênio era uma pessoa esforçada, um técnico bem intencionado. (19Or:Br:Intrv:Com - Manoel dos Santos, 1997)

(10)O início de um racionamento pode ser de 10\%, 20\% ou 30\% do consumo. Não vai começar um racionamento grande. Mas, no Centro-Sul, acredito, ele já é inevitável. (19Or:Br:Intrv:Com - Luiz Otávio Koblitz, 1997)

Por meio das ocorrências acima, observa-se que, em todos os contextos, o verbo acreditar já apresenta nuances que proporcionam a codificação de crença e opinião do locutor, uma vez que, em (7), o locutor relata que, embora esteja buscando melhorar algo, ele confia no potencial, isto é, acredita, dá créditos à pessoa que, possivelmente, é responsável por realizar tal tarefa. $\mathrm{Na}$ ocorrência em (8), nota-se que o verbo acreditar também faz referência a um processamento mental ligado à subjetividade, visto que apresenta uma tomada de posicionamento ligada ao ato de não esperar por mudanças, ou seja, por melhoras, fato que está bastante ligado ao que o locutor julga como uma situação favorável ou não favorável.

A ocorrência em (9) parece bastante semelhante semanticamente, visto que o locutor se posiciona diante da personalidade do ex-secretário Geraldo Eugênio, fazendo um julgamento às atitudes dele, algo que dá ênfase a um traço semântico mais fluido, ligado à modalidade epistêmica. Embora semanticamente seja encerrada uma proposição, há a evidencia de nuance modal, assim como observado nos demais contextos. Em (10), ao assumir configuração parentética, o verbo cognitivo acreditar passa a se comportar como um advérbio modalizador, que, de acordo com Neves (2011, p. 244), tem como característica básica expressar alguma intervenção do locutor na definição da validade e do valor de seu enunciado. Ainda segundo a autora, outras estratégias podem ser adotadas, dentre elas os recursos prosódicos e comentários marginais, que serão observados por meio de outros verbos parentéticos ainda nesta análise.

Outro verbo que expressa um processo mental mais fluido é o verbo pensar, que se relaciona ao ato de combinar ideias, refletir e raciocinar por meio de conhecimentos prévios, os funcionamentos desse verbo podem ser observados entre as ocorrências (11) e (13):

(11) O que escrevi em O jogo (diário esportivo) e repeti no Sabiá (jornal da Casa do Brasil de Lisboa) é exatamente o que penso sobre a atitude desses dois ministros em relação à CPLP. (19Or:Br:Intrv:Com - Alípio de Freitas, 1997) 
(12) Eu penso que deverão surgir medidas especiais para que esse uso da máquina administrativa não aconteça. (19Or:Br:Intrv:Pov - Dom Cláudio Hummes, 1997)

(13) Platão chegou, penso, carregando o seu dossiê à maneira do livro de orações. (19:Fic:Br:Holanda:Burro - O Burro de Ouro, Holanda, Gastão de., 1960)

Na ocorrência em (11), nota-se que o predicado pensar apresenta acepções semânticas que codificam um processamento mental mais fluido, pois, ao utilizá-lo, o locutor faz referência a sua subjetividade, visto que relaciona os conhecimentos prévios e experiências que tem sobre o assunto, o qual leu e escreveu. Em (12) e (13), percebe-se que o verbo, além de desenvolver um processamento mental abstrato, que é característico dele e está correlacionado a atitudes e julgamentos.

Quando o locutor pensa, ele desenvolve um processo mental, ou seja, subjetivo, relacionando seus conhecimentos acerca de algo que está sendo o cerne do seu pensamento. Por meio dessas acepções, observa-se uma forte tendência de o verbo apresentar-se em configuração parentética, como em (13) visto que passa a se aproximar do eixo epistêmico.

Na esteira dos verbos cognitivos que se tornam parentéticos, há o verbo imaginar, que demonstra um percurso bastante semelhante ao de pensar, uma vez que a atividade mental expressa por tal predicado indica um grau de incerteza do conteúdo, revelando, assim, nuances modais epistêmicas. As ocorrências entre (14) e (15) ilustram tais significados:

(14) Ontem, Brasil de Farroupilha e Veranópolis carimbaram passaporte. Temos aí quatro equipes da Serra. \# Rodada \# Emocionante a rodada. Um gol aqui, outro ali e a cada instante tínhamos modificações na tabela. Imagino o sofrimento do pessoal de Vacaria: o time está fora dos pentagonais pelo saldo de gols. (19N:Br:PA - De Primeira/HiltorMombach, 1997)

(15) Estão aí as razões da minha hesitação, quando imagino um novo dilúvio universal e me pergunto que país, nos mais altos interesses da inteligência humana, mereceria o privilégio de construir a arca. (18:Nabuco:Minha - Joaquim Nabuco, Minha Formação)

Entre (14) e (15), é possível perceber que, ao imaginar, é desenvolvido um processamento mental ligado à subjetividade, pois ocorre a criação de uma situação que, de fato, ainda não aconteceu. Ao dizer "imagino o sofrimento do pessoal...”, o falante não está lembrando de uma situação anterior, mas construindo uma imagem do que, segundo suas impressões, possivelmente ocorrem. O mesmo ocorre em (14), visto que o falante não faz referência a algo concreto, mas a uma situação imagética, isto é, que faz parte da sua imaginação, construindo-se de acordo com os conhecimentos e experiências de cada. Quando o falante imagina, há um processamento mental, mas a própria semântica do verbo relaciona-se com aquilo que pode fugir ao real. Imaginar significa formar imagem mental de algo não presente, o que deixa espaço para o que não é um fato, mas uma criação subjetiva. 
Abaixo, nota-se que o verbo imaginar passa por subjetivação, revelando a codificação de atitude e crença do falante. Em (16), percebe-se que o predicado pode ser substituído por verbos como achar/acreditar, porque exprime um funcionamento mais abstrato, quanto ao seu sentido. As nuances de tal predicado possibilitam a expressão de modalidade epistêmica, pois em ambas as ocorrências que se seguem, o locutor busca marcar a sua opinião. Na ocorrência em (17), de verbo pleno, imaginar passa a se comportar como advérbio modalizador epistêmico, apresentando um uso mais abstrato, fato que é possível, por meio de suas acepções, que proporcionam um forte elo entre o eixo cognitivo e o eixo epistêmico, por ser um processo mental que referencia possibilidades, relacionando, assim, o que é próprio de cada falante.

(16) Mesmo tendo passado por um longo período de isolamento, imagino que você tenha sido influenciado por outros coreógrafos. (19Or:Br:Intrv:ISP - Eifman, 1997)

(17) O fato de ler muitos livros me fez entender o gênero de uma maneira mais legal também, imagino. (19:Fic:Br:Abreu:Onde - Marcelo Campos)

Comparando as acepções dos quatro verbos selecionados (acreditar, pensar, imaginar, calcular), pode-se notar que o verbo calcular, embora passe a apresentar um sentido mais abstrato, envolvendo a subjetividade do falante, possivelmente, via metaforização, ainda está bastante ligado ao eixo cognitivo, pois faz referência a um sentido mais concreto, rígido, devido à especificidade do processo que expressa. Nas ocorrências abaixo, observa-se tal rigidez de significado, pois, ao desenvolver um processamento mental ligado ao ato de calcular, ele denota uma atividade mais concreta, isto é, menos subjetiva:

(18) Tudo o que for chamado de ativo ou recebível entra nesta história. Calculo R $\$ 140$ bilhões. Só de privatização, a expectativa é de arrecadar R 68 bilhões. (19Or:Br:Intrv:ISP - Velloso, 1997)

(19) Eternamente grato a não poucas provas de affeição e condescendencia, deixo os remanescentes, que calculo em 200 contos de réis, á minha amante D. Sofia Dias, devendo esse legado transmitir-se em qualquer tempo á successão ligitma ou illegitima, verificada em regra a filiação. (18:Taunay:Entardecer - Afonso de E. Taunay - Ao entardecer)

(20) É uma desilusão que eu tenho com o brasileiro. Calculo que só $20 \%$ dos brasileiros sejam gente como nós, gente que merece respeito e consideração. (19Or:Pt:Intrv:Web - Hélio GRacie)

(21) O berloquezinhol Sabes lá, afiança que já, pegou touros. Com muita aguardente no bucho, calculo eu. (19:Fic:Pt:Tavares:Insubmissos - Urbano Tavares Rodrigues - Os Insubmissos, 1976)

Entre as ocorrências (18) e (21), é possível observar que o verbo calcular faz referência a um processo mental ligado ao raciocínio lógico, que, embora em (21) não seja matemático propriamente dito, expressa a profundidade de certeza que o locutor tem, devido aos seus conhecimentos e análise da proposição. Por meio do mecanismo de habituação, que leva a 
frequência do uso, o verbo calcular passa a ser utilizado em um maior número de contextos, não remetendo apenas a expressão de quantificação, mas de subjetividade, que está ligado a intersubjetividade, devido à preocupação do locutor com a reação do interlocutor (BARBOSASANTOS, 2019).

No que concerne às nuances de tal predicado, nota-se que, quando o indivíduo calcula, semanticamente, é recuperado o ato de computar/fazer contas por meio de dispositivos como o próprio cérebro, além de recursos como lápis e papel, fato que o distancia da expressão da modalidade epistêmica. Ao analisar a ocorrência (18), percebe-se a presença de ambiguidade, pois é possível recuperar a ideia de que o locutor de fato fez um cálculo para posteriormente expressar o seu julgamento e, ao mesmo tempo, tem-se a noção de que ele está apenas julgando, a partir de algumas hipóteses. Nesse sentido, parece ser a metáfora um dos mecanismos determinantes para essa trajetória de abstratização, visto que, partindo de verbos cognitivos como acreditar, pensar e imaginar, o locutor faz uso do calcular, a fim de expor o mesmo significado.

Em Bybee (2010), pode-se notar que, ao tratar de verbos cognitivos do inglês, como think, can, believe, imagine, understand, e outros, não há uma distinção entre o eixo cognitivo e o eixo epistêmico, o que pode ser observado no modo como a autora caracteriza tais verbos logo no subtítulo do capítulo: cognitivos/epistêmicos. Caracterização semelhante ocorre em Criscuolo (2011), que, ao analisar as orações subordinadas substantivas objetivas diretas e indiretas, caracteriza os verbos achar, acreditar, imaginar, pensar, calcular, admitir, e outros, como pertencentes à noção de julgamento, opinião e crença, isto é, sem a distinção das acepções semânticas de tais predicados. No entanto, como se observa a partir das investigações aqui realizadas, nem todos estes verbos revelam, em magnitude, a expressão de modalidade epistêmica desde a origem.

Ao analisar, neste trabalho, as nuances de alguns verbos de cognição no português, foi possível constatar que, contrariamente a alguns trabalhos anteriores, há distinções entre o que é mais cognitivo e o que é mais epistêmico. Neste sentido, com base no quadro abaixo, é possível reconhecer tais nuances, compreendendo melhor a composição semântica de cada verbo analisado.

Quadro 1 - Acepções e processamento mental dos verbos analisados.

\begin{tabular}{|c|c|c|}
\hline Verbo & Acepções & Processamento mental \\
\hline Acreditar & ter fé ou crença, ter como verdadeiro ou provável & Considerar algo real \\
\hline Pensar & meditar, raciocinar, pretender, imaginar & Combinar ideias \\
\hline Imaginar & conceber na mente, idear, criar algo, visualizar & Criar imagens \\
\hline Calcular & determinar valor, Fazer cálculo, avaliar, raciocinar & $\begin{array}{c}\text { Raciocínio lógico que processa } \\
\text { valores/quantidades }\end{array}$ \\
\hline
\end{tabular}

Fonte: elaboração própria 
Por meio da tabela acima, percebe-se que as acepções de cada verbo podem ou não proporcionar a expressão de crença e opinião, pois alguns verbos de cognição se encontram mais próximos da modalidade epistêmica, enquanto outros, mais distantes, por apresentarem nuances de um processamento mental mais concreto. Uma das marcas que revela o funcionamento de advérbio modalizador entre esses usos é a sua cristalização na primeira pessoa do singular do modo indicativo. Tal fato permite que esses predicados deixem de selecionar argumento interno e passem a funcionar apenas com a marca de primeira pessoa, dando lugar, portanto, à expressão de modalidade epistêmica.

Comparando a trajetória desses verbos, notou-se que, embora o predicado calcular também apresente um funcionamento mais abstrato, via subjetivação e parentetização, o percurso desempenhado por ele se difere em vários aspectos. Com base nas nuances observadas, evidenciou-se a existência de um continuum, em que os processos mentais são compreendidos como mapeamentos da trajetória, no sentido de que todos eles passam ou poderão passar por pontos semelhantes na escala.

Dentre os verbos aqui analisados, acreditar, imaginar e pensar, que apresentam nuances mais abstratas desde a origem, foram mais frequentes que o verbo calcular, quando observados em configuração parentética. A baixa frequência de predicados como calcular, nesses contextos de parentetização e modalização, revela que, quanto mais representativo de um processo mental mais fluido, mais propenso o predicado será para expressão de modalidade epistêmica. Calcular, por apresentar significados ligados à computação e lógica matemática, apresenta-se mais distante do eixo epistêmico, como se vê no quadro a seguir.

Quadro 2-A escala da abstratização dos verbos cognitivos parentéticos.

Campo cognitivo

\begin{tabular}{|c|c|c|}
\hline calcular & imaginar & acreditar \\
\hline $\begin{array}{l}\text { [Processos mentais } \\
\text { menos abstratos] }\end{array}$ & $\begin{array}{l}\text { [Processos mentais } \\
\text { mais fluidos] }\end{array}$ & $\begin{array}{l}\text { [Processos ligados a } \\
\text { atitude proposicional] }\end{array}$ \\
\hline & Fonte: elaboração própria. & \\
\hline
\end{tabular}

Os modalizadores no quadro acima, embora não tenham perdido algumas nuances de origem, apresentam mudanças relacionadas ao seu funcionamento de tais itens no uso da língua. Ao comparar as trajetórias dos quatro verbos selecionados, percebe-se que o acreditar é bastante ligado à expressão de opinião e crença do indivíduo, mostrando-se epistêmico por natureza, o que se assemelha aos verbos imaginar e pensar, que, embora ainda expressem ideia de processamento mental, denotam mais facilmente uma avaliação. Em relação ao verbo calcular, nota-se que, embora faça referências a ações mais concretas, expressas pelo ato de calcular/raciocinar, encontra-se em um nível inicial do continuum, visto que, em alguns 
contextos, via subjetivação, o verbo passa a apresentar nuances ora de lógica matemática, ora de crença e opinião.

Consoante Tavares e Freitag (2010, p. 111), na medida em que um verbo vai descendo os degraus da escala de atividade, passa a expressar nuances mais abstratas, perdendo, gradativamente, os elos com o mundo concreto. A partir da subjetivação, ocorre um maior alcance contextual e, consequentemente, maior frequência de uso desses verbos, levando-os a atuarem em diferentes contextos com expressão de modalidade.

\section{CONSIDERAÇÕES FINAIS}

No que compete à representatividade dos dados encontrados, notou-se que os verbos acreditar, pensar e imaginar são mais expressivos do que o verbo calcular, devido as nuances que expressam estarem mais ligadas ao eixo da modalidade epistêmica, enquanto o calcular, por ser mais representativo de um processo mental específico, mostrou-se menos frequente.

A frequência de ocorrência é um dos fatores que parece demonstrar isso, já que verbos menos representativos de uma atividade mental mais concreta são mais frequentes como modalizadores epistêmicos. O verbo calcular, por sua vez, embora também caminhe para a expressão da modalidade epistêmica, tem uso mais limitado quanto à codificação de atitude e avaliação do locutor.

As nuances dos verbos analisados atestam atuações em campos semânticos distintos, uma vez que, diferentemente do que se observou em outros trabalhos, aqui, pode-se evidenciar que, embora o domínio da cognição e o domínio epistêmico sejam limítrofes, há diferenças que permitem compreendê-los separadamente.

\section{REFERÊNCIAS}

BARBOSA-SANTOS, L. A. O uso de verbos cognitivos em construções parentéticas epistêmicas: uma abordagem do ponto de vista da gramaticalização. 2019. 110f. Dissertação (Mestrado em Letras) - Universidade Federal de Mato Grosso do Sul, Três Lagoas, 2019.

BYBEE, J. Language, usage, and cognition. Cambridge, Cambridge University Press, 2010.

BORBA, F. S. Dicionário gramatical de verbos do português contemporâneo do Brasil. São Paulo: Editora da Universidade Estadual Paulista, 1990.

CASTILHO. A. C; CASTILHO, C. M. M. de. Advérbios Modalizadores. In: ILARI, R. (Org.). Gramática do Português Falado. v. II. Níveis de Análise Linguística. Campinas: Unicamp, 1993. 
CASSEB-GALVÃO, V. C. O achar no português do Brasil: um caso de gramaticalização. 1999. 167f. Dissertação (Mestrado em Linguística) - Instituto de Estudos da Linguagem, Universidade Estadual de Campinas, Campinas, 1999.

CRISCUOLO, A. C. S. Orações subordinadas substantivas sob uma perspectiva funcional cognitivista: uma proposta de descrição e ensino. 2011. 155f. Tese (Doutorado em Linguística) - Faculdade de Ciências e Letras, Universidade Estadual Paulista Júlio de Mesquita Filho, Araraquara, 2011.

CUNHA, G. Dicionário etimológico da língua portuguesa. 4. ed. rev. Rio de Janeiro: Lexikon, 2010.

DAVIES, M.; FERREIRA, M. Corpus do Português: 45 milhões de palavras, 1300s-1900s, 2006. Disponível em: http://www.corpusdoportugues.org. Acesso em: 13 ago. 2021.

GONÇALVES, S. C. L. Gramaticalização, modalidade epistêmica e evidencialidade: um estudo de caso no português do Brasil. 2003. 250 f. Tese (Doutorado em Linguística) - Instituto de Estudos da Linguagem, Universidade Estadual de Campinas, Campinas, 2003.

HALLIDAY, M. A. K. An introduction to functional grammar. London: Edward Arnold, 1985.

HENGEVELD, K.; MACKENZIE, Lachlan. Functional Discourse Grammar. A typologicallybased theory of language structure. Oxford, New York: Oxford University Press, 2008.

HOPPER, P.; TRAUGOTT, E. C. Grammaticalization. Cambridge, UK: Cambridge University Press, 1993.

JUBRAN, C. C. A. S Parentetização. In: JUBRAN, C.C.A., KOCH, I. G. V. (Org.). Gramática do Português Culto Falado no Brasil: Construção do texto falado. 1. ed. Campinas - SP: Editora da UNICAMP, 2006, v. I, p. 301-357.

MICHAELIS. Dicionário escolar língua portuguesa. São Paulo: Melhoramentos, 2008.

NEVES, M. H. M. A modalidade In: KOCH, I. G. V. (Org.). Gramática do Português Falado IV: Desenvolvimentos. Campinas: Ed. Unicamp, 1996. p. 163-199.

NEVES, M. H. M. Gramática de usos do português. 2. ed. São Paulo: Editora Unesp, 2011.

PALMER, F. R. Mood and Modality. Cambridge: Cambridge University Press. 1986.

SCHLESINGER, I. Cognitive space and linguistic case. Cambridge: Cambridge University Press, 1995.

SCHNEIDER, S. Reduced Parenthetical clauses as mitigators. A corpus study of spoken French, Italian and Spanish. Amsterdam: John Benjamin Publishing Company, 2007. 
TAVARES, M. A.; FREITAG, R. M. K. Do concreto ao abstrato: influência do traço semânticopragmático do verbo na gramaticalização em domínios funcionais complexos. Revista Linguística. v. 6, n. 1, 2010.

TRAUGOTT, E.C. On the rise of epistemic meanings in English: an example of subjectification in semantic change. Language, Baltimore, v. 65, n.1, p.31-55, 1989.

TRAUGOTT, E. C. From subjectification to intersubjectification. In: HICKEY, R. Motives for Language Change. Cambridge, UK: Cambridge University Press, 2003.

TRAUGOTT, E. C.; DASHER, R. B. Regularity in semantic change. Cambridge: Cambridge University Press, 2001.

Recebido para publicação em: 10 maio 2021.

Aceito para publicação em: 13 jul. 2021. 